\title{
Review of the Implementation of PBL Teaching Model in Chinese College English Education
}

\author{
Zhuofei Luo ${ }^{1, \dagger}$ Yifan $\mathrm{Shi}^{2,}{ }^{*},{ }^{\dagger}$ Yongqi Tang ${ }^{3, \dagger}$ \\ ${ }^{1}$ School of Foreign Language, Zhongnan University of Economics and Law, Wuhan430070, Hubei, China \\ ${ }^{2}$ School of English Studies, Tianjin Foreign Studies University, Tianjin, 300204, China \\ ${ }^{3}$ School of Foreign Language, Shandong Agriculture University, Tai'an, Shandong, 271000, China \\ *Corresponding author. Email: syf001103@email.cu.edu.kg \\ Those authors contributed equally.
}

\begin{abstract}
As English has become the international language across the globe, Chinese higher education institutions has begun to pay more attention to English education. As a new teaching model, Problem-based Learning (PBL) has been widely researched and applied in Western countries, and numerous studies have shown that it has a significant effect on second language acquisition. Although some Chinese scholars have also investigated the integration of this model in college English classrooms in recent years, the scope of studies is still limited and most of them are only based on proposals rather than empirical studies. This paper reviews a number of previous studies to explore the current research of the application of PBL teaching model in Chinese College English education, its implications for both the learners and the education system, as well as the possible strategies for its use. Through the above methods, this paper demonstrates that PBL has critical implications and facilitative effects on the teaching of English in Chinese higher education institutions. It can not only compensate for the shortcomings of the current traditional teaching model of college English, but also promote students' language acquisition and competence in many ways. The implication of this paper is to provide directions for the reform of English education in Chinese higher education institutions, to present the prospect of the integration of PBL in Chinese College English education, and to offer valuable information for future research in this field.
\end{abstract}

Keywords: PBL teaching model, College English education, Chinese higher education institutions, Comprehensive development.

\section{INTRODUCTION}

PBL teaching model was first proposed by John Dewey, an American educator and philosopher, and was applied to the teaching reform of western medical education. Project-based knowledge or project-based learning refers to a kind of teaching completed by students through setting projects related to teaching. Dewey believes that learning and education are interactive social processes. Buck Institute for Education pointed out that PBL teaching is a teaching method in which students learn by actively engaging in real-world and personally meaningful projects [1]. It can be seen that PBL teaching mode is a comprehensive education mode to attract students to actively carry out continuous and collaborative investigations.
PBL is a problem-based teaching method and is different from the traditional one. Its teaching focus is no longer the knowledge infusion, but the students' initiative. With the problem as a guide and motivation, students solve the problem by means of self-study and cooperative learning, then ideal teaching effect can be obtained and the efficiency and quality of college English education can also be improved.

The theoretical research and practice of PBL in China began at the end of the twentieth century, and the research content is gradually deepening and expanding. At the beginning, people only made the introduction of this teaching mode and the discussion of the feasibility of curriculum application. To now PBL is introduced to different stages and different subjects of teaching, and through practice and summary discussion, it has been a relatively perfect formation teaching system. Nowadays, 
PBL has become a new, problem-oriented strategy of education for all-round development, with collaborative learning as method, focusing on students ' learning ability and skills.

\section{PBL AND COLLEGE ENGLISH IN CHINA}

As this paper is reviewing PBL in Chinese colleges, College English is a compulsory course in Chinese universities and colleges. Students in advanced education may get tired of the old-fashion teaching method of college English in which teachers tell them what to read what to recite and no active learning for themselves and finally receive a bad grade in the final exam. The Problem-based Learning can replace the old-fashion teaching and learning method and provide students a new learning experience.

\subsection{The Origin of $P B L$}

The rising up of project-based learning can be traced back to the Italy in late 16th Century. According to Shen, the term "project-based learning" was firstly come up with in 1918 and was only used in engineering and architectural education activities [2]. Later, by the end of the 20th Century, the term PBL was widely promoted and applied in various subjects in the western countries.

\subsection{The Situation of Current Research of PBL in China}

Shen states that the appearance of research of PBL can be traced back to the 1990s [2]. Since 2001, it had been gradually increased, which has been significantly increased after 2006. Overall, the current researches on PBL can be regarded as consisting of three aspects: The first one is theoretical study of PBL, consisting of the researches on the characteristics, theoretical basis, connotation and practical significance of PBL. It focuses to demonstrate the significance and value of PBL, not how to apply it to specific fields. The second is researching interaction of PBL and specific fields. In this sort of researches, the PBL is actually applied to some specific fields. The last is the research of PBL application in real teaching situation supported by modern information technology. Researchers have mainly explored the design or related experiments of Projectbased Learning under the network environment or based on the network platform. With the help of information technology, the method of applying PBL to comprehensive teaching practice or exploring the process of PBL teaching system design under the information technology environment is explored.

\subsection{The Importance of Combining PBL and College English}

According to College English Curriculum Requirements published by People's Republic of China Ministry of Education "College English is a teaching system guided by foreign language teaching theory, with English language knowledge and application skills, crosscultural communication and learning strategies as the main content, and a variety of teaching modes and teaching methods as one" [3]. The Requirement also states that the goal of college English teaching is ' to cultivate students ' comprehensive English application ability, especially listening and speaking ability.' The traditional classes mainly focus on teachers while students are low in active learning and receive knowledge passively. To cultivate students' comprehensive English application ability, teachers may need to change their teaching method. According to Zhi, one of the goals of the change is to help students form their own study style and gain progress in their ability to do self-directed learning [4]. Being the subject of self-directed learning, students can plan the content, the goal, the method of the study and evaluate the progress and output.

PBL, student being its subject, is a system based on a specific project where students can gain knowledge during the process and development in their self-directed learning. Studying a language casts a long period of time. In the studying progress, self-directed learning ability is of great importance because if students only have limited studying opportunities in only the class time, the language may be difficult for them to master. Now college English teaching and studying are faced with some problems including too many contents, limit teaching time and interaction between students and teachers, putting restraint on teaching effect. To solve these problems and effect caused by them, not only change in current teaching and studying method, but also the improvement in selfdirected learning ability is needed. PBL is conducive to teacher education development, classroom reform and innovation. It helps to change the way students study and contributes to independent, cooperative, inquiry learning ability, which is advantageous to the study interest raise and the development synthesis thought ability. Therefore, combining the PBL and college English teaching and studying is of positive meaning.

\section{THE IMPLICATIONS OF PBL TEACHING MODEL ON COLLEGE STUDENTS' COMPREHENSIVE DEVELOPMENTS}

There are many previous studies have proved that the PBL teaching model can enhance both student learning performance and various competencies, but the majority of them are based on western contexts. In recent years, some Chinese scholars have started to conduct substantial 
empirical research on the application of PBL model into Chinese College English education, whose results demonstrated the effects of PBL on the cultivation of students' capacities in Chinese context. The authors will review the above mentioned literature, focusing on summarizing the implications of PBL teaching model on college students' English language competence, critical thinking ability and learner autonomy.

\subsection{The Influences of PBL on English Language Competence}

Many researchers have carried out empirical studies by integrating the PBL teaching model in Chinese College English classrooms with the aim of verifying whether the model can effectively improve students' English language competence. Zhang conducted a classroom observation experiment with English presentation as the main project to demonstrate the benefits of project-based activities in students' comprehensive English proficiency, especially listening and speaking skills [5]. Although the result of this experiment seems to be convincible and reliable, it still lacks sufficient data to support, meaning that the authors' subjective judgments may to some extent deviate from the actual situation.

Through a 16-week experiment of integrating PBL teaching model into the Chinese College English classroom, Zhang and Lin holds the view that students' English listening, reading, and writing skills can be effectively improved through various classroom activities and exercises such as oral reports, English presentations, critical reading tasks [6]. By effectively and accurately analysing students' performance in different modules of CET-4 before and after the semester, the argument that the PBL teaching model can enhance students' English language skills is validly proved. However, although the research method used by Zhou is similar to Zhang and Lin, the research result fails to prove that PBL's function in promoting students' English proficiency [7]. The failure of the study to achieve the expected results may be related to the short duration of the experiment (only 12 weeks) and the lack of rigorous data analysis process (only the total score of CET-4 was analysed, instead of individual modules).

According the results of the English tests and questionnaire, Shen argues that the PBL teaching model improves students' classroom performance as well as their English performance by stimulating their interest in learning [2]. Unlike the teacher-centered traditional teaching model, PBL provides learners with a more vivid classroom environment, thus contributing to the progress of their English language competence in four aspects: listening, speaking, reading, and writing. In conclusion, although most of the previous studies are only exploratory investigations, the findings of the majority of them still indicate and prove that PBL teaching model has a facilitating effect on the enhancement of learners English language competence.

\subsection{The Effect of PBL on Cultivating Critical Thinking Ability}

In addition to the function of improving students' English language competence, previous researches have also examined the effectiveness of the PBL teaching model on improving students' critical thinking ability. Through a three-year classroom experiment, Tiwari et al. argued that PBL courses are more effective than traditional classes in facilitating critical thinking ability of college students, and the experiment learners' improvements in this respect were maintained even 2 years after the experiment ended [8]. In this paper, The California Critical Thinking Disposition Inventory (CCTDI) by Facione was used to measure students' critical thinking ability and the results were analysed by qualitative research methodology, thus it is reliable and academic enough to demonstrate the advantage of PBL teaching method [9].

Recently, many Chinese researchers also tried to verify the function of PBL teaching model on students' critical thinking ability when applied in College English education. For example, based on CCTDI, both Zhang \& Lin and Zhou held the view that PBL can significantly enhance four critical thinking dispositions of College English students--interpretation, analysis, explanation and evaluation, but the improvement in self-regulation and reasoning was not significant [6][7]. PBL students' critical thinking skills was improved to a certain extent by defining the problem, analysing the material, demonstrating the procedure, presenting the results, selfassessing, and peer assessing in PBL classroom.

\subsection{PBL's Effectiveness in Fostering Learner Autonomy}

According to Shen and Zhang, after one semester of integrating PBL in College English, both studies indicate that PBL can significantly enhance learning motivation and thus fostering learner autonomy and cooperative skills [3][5]. Although their experiments were only based on questionnaires and lack of rigorous data analysis, the results can still to some extent reflect that problem-based activities, such as role-playing and solving problems in groups are beneficial to the cultivation of students' comprehensive learning abilities.

McCarthy states that PBL is limited to cultivating leaner's independently leaning ability because the concept of learner autonomy originated in the Western world and most students in oriental countries value the acquisition of credits more than comprehensive competencies [10]. Even though the results of this study may be limited by the short duration of the experiment, it still can provide an insight into the incorporation of PBL 
in Chinese College English education. It is important to reform the educational system as a whole and raise the awareness of students' comprehensive development.

\section{PROBLEMS IN EDUCATIONAL PRACTICE}

When implementing PBL teaching methods in authematic classroom contexts, it is not difficult for us to find some existing problems as below.

\subsection{Dysfunctional Cooperative Groups}

In the practice of PBL, each group may pay more attention to the work progress and problem solving process of its own group, and pay relatively little attention to the research problems and process of other groups, which will have a negative impact on learners' acquisition of systematic knowledge. Also, because of the differences in individual abilities, interests, personality and other factors, some groups cooperate very well and solved problems quickly, while some groups cooperate very little and solve problems slowly. In addition, Dolmans et al. investigated the occurrence of critical incidents in cooperative groups. These studies demonstrated that lack of elaboration, lack of cohesion and lack of motivation highly inhibited the learning process in PBL [11][12][13].

\subsection{More Demanding Design and Implementation Environments}

PBL needs a rich learning environment or external conditions. According to Li et al., PBL's environmental problems can be consisted of five elements--people, things, space, time and content [14].

Schools, teachers and students need to invest much more time, energy and even money than traditional teaching methods. If the hardware and software resources for scientific research in schools are not advanced, students have more courses to learn, and teachers have heavy teaching tasks for other courses, then this becomes the largest obstacle to the implementation of PBL.

\subsection{Changes of Concept Brings Severe Challenges for Teachers and Students}

In the PBL tutorial group, after students' having questions in mind, some students still hope that the teachers tell them the answers directly, rather than actively exploring and finding the answers on their own. In addition, some students evade their responsibilities and cope with tasks in group activities. All these phenomena need teachers to guide or correct them actively and effectively, then students' old learning concepts can be reformed and new teaching concepts -independent learning, lifelong learning and cooperative learning can be established. This shift in teacher's role is a new challenge for many teachers.

\section{HOW TO SOLVE PROBLEMS WITH PBL IN EDUCATIONAL PRACTICE}

\subsection{Developing Students' Ability of Self- directed Learning and Cooperative Learning}

Vermunt et al. holds the view that, in order to challenge students and stimulate them towards selfdirected learning, there should be a constructive friction between the degree of student and teacher regulation [15]. Students are the main body of learning, teachers and students have equal status, and students' dependence on teachers should be greatly reduced. What is needed in PBL is a transition from tutor regulation, or external guidance through shared guidance in which the student and the tutor together guide the learning process to student regulation or internal guidance [16]. To improve corporative group functioning and stimulate students towards collaborative learning, tutors should evaluate the functioning of their group on a regular basis. Furthermore, tutors should learn how to deal with problems of group dynamics [13]. If the problems used are more complex and ill-structured and if there is constructive friction between student and tutor guidance, there would be a better chance that interactions in the group that enhance student learning and the collaborative learning process will occur.

\subsection{Teachers' Guiding Principles as Facilitators}

In PBL teaching practice, students often encounter problems of one kind or another in the process of solving problems. Faced with these complicated problems in reality, many students often feel frustrated. Therefore, there is a need for teachers to help students with problem solving strategies, which is essential for successful group problem solving. For example, $\mathrm{Hu}$ et al. illustrates teachers' guidance including the following aspects: information collection, analysis, processing, evaluation of guidance, guide the study group to determine group goals and the guidance of problem solving strategies [17].

First, teachers in PBL should follow the rules of information collection, analysis, processing, and evaluation of guidance. Guidance in this area includes methods, procedures and tools of literature review, internal and external criticism of the collected literature, etc. Some researchers have proved that students have the greatest difficulty in this area, thereby carrying out PBL, students' information literacy and access should be integrated. The cultivation of processing ability is in the first place. In addition, Bransford and Schwartz argues that given the influence of previous knowledge, students should be confronted with contrasting problems, because 
they are helped to appreciate the critical features of new information, to evaluate new information critically and to change their views when necessary [18].

Second, teachers in PBL should guide the study group to determine group goals. Due to the long-term influence of traditional teaching, students' learning goals and tasks are basically determined by teachers. Therefore, at the beginning of PBL, many groups may not have clear goals and division of labour, leading to slow progress in problem solving and group cooperation. When this happens, teachers need to strengthen guidance, so that students can change their ideas and learning methods as soon as possible and gradually learn to determine group goals and tasks autonomously. In addition, the coins also need to timely check the completion of tasks and objectives.

Third, teachers should base on the guidance of problem solving strategies. As the previous teaching methods are mainly based on direct teaching of knowledge in the classroom and extracurricular students' individualistic learning, students have too much dependences on teachers and lack of real cooperation spirit and skills among students for a long time. According to Che et al., however, in PBL teaching model, teachers are no longer the only knowledge base, but the builders of knowledge [19].

Teachers play the role of resource provider and facilitator of student development, and their task is basically to guide learners in the process of problem solving. As the learner becomes more proficient in problem solving, the teacher gradually takes a back seat.

\subsection{Systematic Learning of Basic English Knowledge is the Premise of Implementing PBL}

In practice, we find that learners around the problem solving and knowledge learning tend to be scattered. It is more conducive to further learning, and students in the process of collaborative problem solving one of the biggest difficulties is the lack of a good command of basic knowledge system of college English ability. Therefore, we believe that before implementing PBL, it is best for learners to master the basic knowledge of college English, because the basic knowledge is the basis for students to solve complex practical problems. The same is true of college English learning.

\section{CONCLUSION}

Based on the background information and the research problems discussed in the introduction chapter, the purpose and main aim of this paper is to put forward a review of previous research about implementing PBL teaching model in college English education in Chinese colleges and universities. The introduction of PBL teaching model provides a new idea to the reform of traditional teaching methods in education practices to explore new learning methods and solved urgent problems in the current postgraduate curriculum reform in China's higher education institutions.

The paper is divided into three parts: the first part discusses the current development status and implementation background of PBL in college English teaching, the second section reviews a large amount of literature and experimental data in order to demonstrate the influence of PBL teaching method on college students' comprehensive ability. And the results indicate that the PBL teaching model can significantly improve learners' English language competence, critical thinking ability and learner autonomy. The third part exemplifies some existing problems of introduction of PBL model in educational practice, such as dysfunctional cooperative groups, demanding design and implementation environment, change of teaching concept for teachers and learning concept for students, etc. and lastly put forward a series of solutions to the PBL problems.

The implication of this study is to explore the influence of PBL teaching model on improving the traditional teaching model and its effectiveness in enriching students' skills and ability in the education of English in Chinese colleges and universities. This paper also provides some reference for Chinese higher education institutions to improve the quality of College English teaching method and offer valuable directions for future research in this field.

\section{REFERENCES}

[1] Buck Institute for Education. (2021). What is PBL?. Retrieved 26 September 2021, from https://www.pblworks.org/what-is-pbl

[2] Shen, Z.W. (2018). The Application of PBL in College English Teaching. Studies in Literature and Language, 17(1), 65-71.

[3] People's Republic of China Ministry of Education Department of Higher Education (2007). College English Curriculum Requirements Beijing: Foreign Language Teaching and Research Press

[4] Zhi, Y. (2009). PBL's Application in China's Foreign Language Education-Meaning, Dilemma and Outlet. Foreign Language and Foreign Language Teaching, 7.

[5] Zhang, Y. (2015). Project-based learning in Chinese college English listening and speaking course: From theory to practice. Canadian Social Science, 11(9), 40-44.

[6] Zhang, J., \& Lin, H. (2018). An empirical study on the influence of PBL teaching model on the critical 
thinking ability of non-English majors. Journal of Language Teaching and Research, 9(6), 1293-1300.

[7] Zhou, Z. (2018). An Empirical Study on the Influence of PBL Teaching Model on College Students' Critical Thinking Ability. English Language Teaching, 11(4), 15-20.

[8] Tiwari, A., Lai, P., So, M., \& Yuen, K. (2006). A comparison of the effects of problem - based learning and lecturing on the development of students' critical thinking. Medical education, 40(6), 547-554.

[9] Facione, N., Facione, P., \& Sanchez, C. (1994). Critical Thinking Disposition as a Measure of Competent Clinical Judgment: The Development of the California Critical Thinking Disposition Inventory. Journal Of Nursing Education, 33(8), 345-350.

[10] McCarthy, T. (2010). Integrating project-based learning into a traditional skills-based curriculum to foster learner autonomy: An action research. The journal of Kanda University of International Studies, 221-244.

[11] Dolmans, D. H., Wolfhagen, I. H., Van Der Vleuten, C. P., \& Wijnen, W. H. (2001). Solving problems with group work in problem - based learning: hold on to the philosophy. Medical education, 35(9), 884-889.

[12] Dolmans, D. J. H. M., Wolfhagen, I. H. A. P., Van Der Vleuten, C. P., \& Winjnen, W. H. F. (2001). Why aren't they working. Problem-Based Learning. Case Studies, Experience and Practice. Case Studies of Teaching in Higher Education. UK: Kogan, 2001.

[13] Dolmans, D. H., Snellen-Balendong, H., \& Van Der Vleuten, C. P. (1997). Seven principles of effective case design for a problem-based curriculum. Medical teacher, 19(3), 185-189.

[14] Li M., Xu C. L.\& Hu W. (2001). Curriculum Development and Teaching Design of PBL.China Audio-visual Education,173(6),8- 11.

[15] Vermunt, J. D., \& Verloop, N. (1999). Congruence and friction between learning and teaching. Learning and instruction, 9(3), 257-280.

[16] Ten Cate, O., Snell, L., Mann, K., \& Vermunt, J. (2004). Orienting teaching toward the learning process. Academic Medicine, 79(3), 219-228.

[17] $\mathrm{Hu}$ X.Z., Ruan H., Wang H.\& Zhang J.M.(2007).The Enlightenment of PBL to College English Teaching Design. Journal of Yibin University(07),110-112.
[18] Bransford, J. D., \& Schwartz, D. L. (1999). Chapter 3: Rethinking transfer: A simple proposal with multiple implications. Review of research in education, 24(1), 61-100.

[19] Che C.L., Guo Q.F., Zhang Y.M., Huo J.M. \& Zhang W.(2010).Thoughts on the application of PBL teaching mode in China's higher medical education. China Higher Medical Education (01),126-127. 